\title{
Formação de professores: um diálogo a luz da Andragogia e da neurociência do aprendizado
}

\author{
Teacher training a dialogue in the light of andragogy and learning neuroscience
}

\author{
Maria Ursulla Jurema Borges*, Aldicea Craveiro de Lima Ferreira*, Maria Erinete Reis Vilas Boas*, \\ Tacildo de Souza Araújo*, Alysson Brhian de Souza Muniz Silva*, Luzia Mara dos Santos** \\ *Instituto Federal de Educação Ciências e Tecnologia do Amazonas/ IFAM-CMC, **Núcleo de Estudos e Pesquisas e \\ Psicopedagogia Diferencial/NEPPD. Brasil
}

\begin{abstract}
Resumo
Neste artigo, é discutido inicialmente, a análise dos conhecimentos atuais da Neurociência do Aprendizado e sua relação direta na compreensão dos processos mediadores e estratégicos de ensino da matemática, considerando como o cérebro aprende e todos os mecanismos neurológicos desenvolvidos no processo de ensino-aprendizagem. Com o intuito de levar adultos de uma turma de Segundo Segmento da EJA, - ensino fundamental a superar disfunções cognitivas lógico-matemáticas. Neste contexto, é fundamental que o profissional docente aproprie-se de tais conhecimentos, pois com a ocorrência do diálogo Neurociência/ Andragogia, está claro a possibilidade de aprimoramento do processo ensinoaprendizagem.

Palavras-Chave: Neurociência da Aprendizagem, Andragogia, Educação de Jovens e Adultos, Didática da Ciência Matemática, Estratégias de Ensino.
\end{abstract}

\begin{abstract}
In this article, is discussed first, the analysis of current knowledge of Neuroscience of Learning and its direct relationship in understanding the mediators and strategic processes of mathematics teaching, considering how the brain learns and all the neurological mechanisms involved in the teaching-learning process. In order to take adult a group of Second Segment of adult education teaching fundamentalist overcome logical-mathematical cognitive dysfunction. In this context, it is essential that the teaching profession to take ownership of such knowledge as to the occurrence of Neuroscience dialogue / Andragogy, it is clear the possibility of improving the teaching-learning process. Keywords: Neuroscience of Learning, Andragogy, Youth and Adult Education, Teaching of Mathematics Science, Teaching Strategies.
\end{abstract}

\section{Introdução}

A atual conjuntura da situação educativa no segmento do ensino de jovens e adultos vem apresentando mudanças significativas e, nos deparamos com situações nas mais diversas Instituições de Ensino que, imprimem dificuldades e falta de domínio didático-pedagógico por parte da maioria dos atores que constituem peças fundamentais no processo de ensino e aprendizagem, haja vista, que as necessidades dos estudantes se tornam ainda mais visíveis, requerendo principalmente do docente, uma postura coerente com as necessidades dos desses alunos. Nesse sentido, em pleno trabalho de formação docente que hora vimos construindo, percebemos então, a grande importância de conhecimentos que dentro das faculdades de licenciatura pouco se tem trabalhado - o que de imediato percebemos uma falta de conexão na elaboração dos desenhos curriculares de formação docente e às necessidades básicas de aprendizagem impar para os alunos que hora nos remetemos nessa pesquisa, portanto, deixando lacunas significativas tanto de habilidades como de compreensão do contexto educacional e seus desafios no ensino de jovens e adultos na ação profissional dos professores. No caso desse estudo prático, um dos saberes que hoje, muito nos ajuda no domínio de como o sujeito aprende a aprender está, na Neurociência, por estes nos levar a cada avanço de estudos e pesquisas, a compreensão das diversas facetas que constituem as funções cognitivas do processo de aprendizagem. Mas também traçarmos relações com outros conteúdos, como a Andragogia e a Didática da Ciência Matemática que muito nos levaram a reconhecer que na ação de ensinagem, no cotidiano do aluno, tudo que se houve, se vê e discute são peças chaves para suas funções cognitivas se desenvolverem com maestria alcançando o seu maior desempenho de compreensão conceitual contextualizado, logo maior poder de resolução de situações-problemas, com significativas mudanças de atitudes tanto em vida privada quanto em suas relações interpessoais.

\section{Marco Teórico}

Ao longo de todo um percurso da pesquisa, percebeuse o quanto os fundamentos da Neurociência são ainda desconhecidos dos professores e distanciados da Educação em todo seu âmbito. Tal discernimento conduziu os estudos, abrindo novas perspectivas e aos poucos, foi-se esboçando um texto capaz de orientar educadores na utilização do conhecimento da Neurociência e apresentar o estudo do cérebro como um dos elementos essenciais para a efetivação desse diálogo no processo de ensino-aprendizagem em Matemática, na 
modalidade da Educação de Jovens e Adultos/EJA. Para tanto, a construção de um texto que pudesse ilustrar todas essas situações, adveio da ânsia que nos acomete ao nos depararmos com situações de ensino em que não conseguimos atingir os canais de entrada dos alunos para que a aprendizagem aconteça com excelência em sua máxima de aproveitamento das habilidades cognitivas dos alunos. Os estudos nos ajudaram muito enquanto professores, no conhecimento de forma mais dinâmica de como o funcionamento do cérebro se apresenta no período da aprender do aluno adulto, claro que procurando sempre estabelecer vínculos com a Andragogia, parte da pedagogia a qual norteia a EJA, e, a partir daí, promover as mudanças necessárias nas ações de preparo das aulas, na execução das mesmas e, sobretudo, promover atividades diversificadas cientificamente balizadas com possibilidades de levar o aluno a tomar sua construção de saber, nas mãos, e assim, reconhecer às próprias necessidades de investidura na construção de seu conhecimento, sob a possibilidade de evolução e crescimento. Logo, analisar e compreender a dimensão do cérebro, segundo a Neurociência tornou-se elementar e norteadora ao processo de ensinoaprendizagem em Matemática, visando contribuir e resignificar a formação de professores de maneira geral no âmbito da educação do ensino público.

\section{Como o cérebro aprende}

Atualmente a Neurociência é uma das áreas que mais avançou em termos de investigação e indagação sobre o impacto do ensino e do que se aprende realmente. Ao pensarmos no tema, a primeira impressão é de algo extremamente complexo, ou seja, a tendência é atribuirmos imediatamente $o$ assunto a medicina. Entretanto, ao mapeamos elementos que fazem um diálogo com a Neurociência e a rota que constitui o Ensino-aprendizagem em Matemática, percebeu-se que isso é possível e que o ambiente escolar é propício para esse diálogo, afinal, parte dos saberes mais elaborados inicia-se dentro da escola.

Podemos crer que a Neurociência lida com os mecanismos biológicos às estruturas cerebrais, as doenças mentais, a cognição, o sistema nervoso, as emoções. Conhecer o funcionamento cerebral é conhecer como o conhecimento humano vem a se organizar, e, portanto, torna-se tarefa respeitável ao redimensionamento do ser humano.

Em nosso cérebro existem aproximadamente 100 bilhões de neurônios (Célula nervosa) cada um com capacidade para efetuar milhares de ligações com outros neurônios (BEAR; CONNORS; PARADISO, 2002, p. 690). Isso cria em nossa cabeça uma verdadeira "rede neural", responsável pela captação, comunicação, recepção, armazenamento e transmissão de informações, mesmo quando estamos dormindo.

Mas, como o cérebro aprende? Se estiver claro que a aprendizagem, assim como nossas funções mentais (memórias, pensamentos, razão, emoção, etc.), se dão no cérebro. É importante enfatizar que algumas indagações ainda permanecem sem respostas e vem sendo alvo de estudos em diversas pesquisas, inclusive em andamento.
Entretanto, não se torna inválido que os educadores tomem conhecimento sobre o que os avanços das neurociências têm a dizer até o momento sobre o assunto, e de que modo esses conhecimentos podem interferir na prática em sala de aula. Pois, tendo em vista que aprendizagem ocorre no cérebro e que este processo está diretamente ligado ao conhecimento de como o cérebro funciona. Isso requer então o conhecimento sobre a célula nervosa e sua peculiaridade funcional no momento, e, de como a aprendizagem se estrutura na mente.

\section{Ativando as sinapses}

A unidade básica celular do Sistema Nervoso é o neurônio ou célula nervosa. Um neurônio típico apresenta corpo celular (onde se encontram o, núcleo, o citoplasma e o citoesqueleto $^{1}$ ) e seus prolongamentos celulares que podem ser subdivididos em dendritos e axônio. Por possuírem características muito peculiares, os neurônios são células altamente estimuláveis capazes de perceber as mínimas variações que ocorrem em torno de si, reagindo com uma alteração elétrica chamada impulso nervoso. Além disso, as células nervosas podem estabelecer milhares de conexões entre si, ou seja, cada um desses neurônios irá se conectar (estabelecendo as sinapses $^{2}$ ) com cerca de mil a mil de outros neurônios para formar o mínimo de 100 trilhões de conexões chamadas sinapses, ocorrendo então a neurotransmissão. Conforme Domingues sobre o "tripé da mielinização", nutrição adequada, estimulação e o afeto (2007 p 27).

- A nutrição adequada se dá ainda com a mãe na fase gestacional, quanto da criança nos seus anos formativos, pois a nutrição é responsávelpelo suprimento do material da qual a mielina é constituída: proteínas e lipídios.

- A estimulação está diretamente ligada ao bem estar do neurônio, ou seja, sem estímulos os neurônios "murcham" e perdem sua capacidade funcional podendo vir a desaparecer. Lembrando que a estimulação deve ser adequada, sem falta ou excesso, propiciando a mielinização.

- $\mathrm{O}$ afeto embora pareça bastante subjetivo, esse aspecto proporciona ausência de estresse e segurança necessária para a maturação neural.

\section{$O$ contexto escolar}

A educação formal e a informal são tipos de interações que podem favorecer, ou não, nossas sinapses, levandonos, ou não, a aprendizagem. Temos então a relevância para o aprofundamento sobre o assunto, pois "o treino e a aprendizagem são interações que podem levar a criação de novas sinapses e a facilitação do fluxo de informações dentro de um circuito nervoso. Por outro lado, o desuso, ou uma doença como o acidente vascular cerebral/AVC, podem fazer com que as ligações sejam desfeitas, empobrecendo a comunicação nos circuitos nervosos, atingidos assim o potencial de aprendizagem, inclusive, pode levar não só ao aumento da complexidade das ligações em um circuito até então independentes, mas neutralizá-los por completo podendo ocorrer a norte da célula neural. "É o que acontece quando aprendemos

\footnotetext{
${ }^{1}$ São neurônios artificiais estruturados numa aproximação a computação baseada em ligações em rede.

2 Relação funcional de contato entre as extremidades/terminações das células nervosas.
} 
novos conceitos a parti de conhecimentos já existentes" (CONSEZA; GUERRA, 2011, pág. 36).

Temos então que a aprendizagem pode ser compreendida como o processo pelo qual o cérebro reage aos estímulos do ambiente ativando os neurônios a formar novas sinapses, tendo em vista que o cérebro em toda sua complexidade e magnitude produz mudanças no organismo para responder as mudanças ambientais relevantes, conservando-as para o futuramente interagir com o meio ambiente.

Por conseguinte, temos que se a aprendizagem é o processo pelo qual o cérebro reage aos estímulos do ambiente com novas conexões, logo o ensino bem sucedido é aquele capaz de afetar as funções cerebrais provocando alterações na taxa de conexões sinápticas. Observando por este ângulo, é compreensível que a qualidade da intervenção pedagógica, portanto altera o cérebro no que diz respeito a sua funcionalidade.

\section{Ensinando os adultos}

Em vista que o processo de construção do cérebro é bastante complexo, compreendemos que sua construção se dá ao nascermos. Segundo Kolb e Whishaw (2002), "O processo de construção de um cérebro é complexo demais para ser codificado integral e precisamente por genes... É deixado parcialmente em aberto, especialmente em relação à tarefa de formar conexões adequadas entre as células".

Por conseguinte, é válido que as estratégias de ensino e a melhor contextualização dos procedimentos devem atender e apropriar-se ao processo cognitivo do adulto. Sendo compreensível a afirmação de (PICONEZ,2002) com relação ao potencial humano: "O homem constituise como membro do grupo por meio de sua identidade pessoal e cultural. Ao nascer como espécie, apresenta grande plasticidade, com o potencial para aprender e desenvolver várias formas de comportamento, utilizando-se diferentes recursos, estratégias e raciocínios, para se inserir no meio em que vive e participa".

O conceito de Andragogia segundo Silva (2004) foi definido em 1965 pelo professor americano Malcom Knowles e refere-se a um conceito de educação para adultos. Temos então que Andragogia é a ciência que estuda as melhores práticas para orientar adultos a aprender. E de acordo com Tamarozzi (2009) que em estudos mais antigos, sobre esse assunto e que fora realizado por Lindeman (1926), que identificou pelo menos cinco pressupostos-chave para a EJA, os quais mais tarde se transformariam em suporte para outras pesquisas, que foram eles:

1. Jovens e adultos são motivado a aprender; por isso, à medida que, experimentam, suas necessidades e interesses são satisfeitos. Por isso, esses são os pontos mais apropriados para se iniciar a organização das atividades de aprendizagem do adulto.

2. A orientação de aprendizagem do adulto está centrada na vida; por isso, as unidades apropriadas para organizar seu programa de aprendizagem são as situações de vida, e não as disciplinas.

3. A experiência é a mais rica fonte para jovens e adultos aprenderem; por isso, o centro da metodologia da educação do adulto é a analise das experiências.

4. Jovens e adultos tem uma profunda necessidade de serem autodirigidos;por isso, o papel do professor é engajar-se no processo de mútua investigação com os alunos, e não apenas transmitir-lhes seu conhecimento e depois avalialos.

5. As diferenças individuais crescem com a idade; por isso a Educação de Jovens e Adultos deve considerar as diferenças de estilo, tempo, lugar e ritmo de aprendizagem de cada aluno.

Nessa perspectiva, ao analisarmos os princípios andragógicos citados neste trabalho, até o momento, nos é possível enxergar a importância de se encontrar estratégias de ensino que mobilizem as vivências, as experiências e, acima de tudo, as demandas motivacionais do aluno da EJA. Tudo isso, torna-se fonte rica para a aprendizagem neste segmento, sendo cabível então que, as aulas sejam enriquecidas, com atividades prazerosas caracterizadas inclusive na diversidade de tarefas e recursos matemáticos que desafiem a construção das ideias matemáticas aplicadas na solução de problemas no campo escolar, bem como, no contexto sociocultural dos alunos e alunas.

Viabilizar a troca de experiências possibilita e habilita o aprendiz, ir à busca,compreender o imediato. O que na prática, significa tornar a solução de problemas profissionais e pessoais, fazendo toda diferença em seu cotidiano, tendo melhor assimilação quando o assunto é de valor utilitário, e, são motivados a aprender conforme vivenciam necessidades e interesses que a aprendizagem por si só se encarrega de propiciar.

$\mathrm{O}$ aluno jovem ou adulto, precisa agir sobre o objeto de estudo de maneira que a tarefa lhe proporcionada em aula lhe desafie o poder de articulação mental, agindo sobre o objeto de estudo para transformá-lo em idéias de sua compreensão, dessa maneira o levando a compreender o modo de como pode ser construído seu conhecimento a partir de si mesmo.

É importante então, que todo professor e professora, mestres e/ou doutores, reconheçam e que procedam na auto-aprendizagem do vasto conhecimento e discussões a cerca da neurociência, Andragogia, didáticas, planejamento e da diversidade das atividades precisas, para que a aprendizagem ocorra em sala de aula para que haja, uma constante, na solução de situações problemas para além dos muros escolares vividos pelos alunos da EJA.

Dessa maneira é importante que os educadores compreendam como ocorre a aprendizagem nas diferentes etapas da vida, tendo em vista, que hoje a escola se depara com públicos cada vez mais diversificados e muitas das vezes exigente, questionador - portanto, é preciso atendê-los em suas particularidades, principalmente quando pensamos em educação de qualidade e com equidade - pois o aluno da EJA em si só 
já apresenta uma longa trajetória de vida e de experiências, como bem pontua: Fonseca (2007) quando afirma que há necessidade de desenvolver um trabalho pedagógico direcionado para as características dos sujeitos, principalmente na educação de adultos, em que o aluno precisa encontrar a funcionalidade da matemática em sua vida. O que em perspectiva torna-se cada vez mais evidente a necessidade de contextualizar o conhecimento matemático a ser transmitido ou construído, não apenas inserindo-o numa situação-problema, ou numa abordagem dita 'concreta', mas buscando suas origens, acompanhando sua evolução, explicitando sua finalidade ou seu papel na interpretação e transformação da realidade com a qual o aluno se depara e/ou de suas formas de vê-la e participar dela. (FONSECA, 2007, p. 55)

\section{Método}

Como estudo qualitativo, esta pesquisa conjuntura uma característica, fundamentada, no estudo descritivo, onde cada detalhe ganha significado na busca da compreensão do tema estudado, pois: "[...] a abordagem da investigação qualitativa exige que o mundo seja examinado com a ideia de que nada é trivial, que tudo tem potencial para construir uma pista que nos permita estabelecer uma compreensão mais esclarecedora do nosso objeto de estudo". (BORGAN; BIKLEN, 1994, p. 49). Para obtenção dos dados da pesquisa nos utilizamos de dois procedimentos básicos: pesquisa bibliográfica e documental.

Através da pesquisa bibliográfica, também denominada de pesquisa de fontes secundárias (MARCONI, LAKATOS, 1996), procurou-se realizar o aprofundamento da literatura existente como: livros, pesquisas, artigos, publicações diversas, dados bibliográficos acessados por computador - e nessa perspectiva sedimentando de maneira bem mais apropriada, nossas inferências, pré-conceito e, sobretudo, o olhar avaliativo sobre o contexto da educação de jovens e adultos. O que nesse sentido de forma direta, repaginou o conteúdo e forma da maneira que se tinha, no ensinar jovens e adultos. E, mediante o levantamento de referências que abordam o assuntoda Neurociência da Aprendizagem, Andragogia, Educação de Jovens e Adultos, Didática das Ciências Matemática, Estratégias de Ensino, no intuito de subsidiar a análise da problemática investigada foi reestruturadas as ideias, paradigmas e seus procedimentos com o intuito amadurecimento cientifico.

\section{Resultados}

Os trabalhos desenvolvidos nos levaram de maneira segura re-significar nossos conceitos e pré-conceitos relacionados a EJA. Pois ser professor de matemática não nos remete ser o matemático, muito menos, o dono do saber matemático, a ponto de não dar importância que, dúvidas, são benéficas quando servem para nos levar a uma reflexão aprofundada sobre o verdadeiro papel do professor de matemática e sua contribuição social dentro de uma sociedade invadida pela inteligência artificial - pelo conteúdo virtual e seus meios de difusão - que mal pode ser compreendidos, por um jovem dito, bem formado, quiçá por indivíduos que experimentam a distorção séria/idade escolar, ou por não terem aprendido no tempo certo a sistematizar seus conhecimentos prévios e em processo de aquisição, seja por déficits de formação escolar ou terem experimentado a incapacidade de professores de saber e conhecer as rotas que levam um aluno a aprender a aprender. E mais grave de tudo isso, é nossa percepção quanto ao elevado numero de jovens e adultos que estão fora da sociedade que nos dias de hoje mais cresce: a sociedade da informação versus a do conhecimento.

Desse modo, saber matemática implica termos domínio sobre os números e suas várias facetas matemáticas - seja numero natural ou racional; das operações nas diversas colocações conceituais como, propriedades, multiplicidade de algoritmos em suas operações, as medidas, construções e interpretações de gráficos e tabelas, geometria, etc. Conhecer profundamente os números e seus campos de aplicação, sem dúvida, faz do professor um profissional mais competente, consequentemente terá maior domínio dos métodos e estratégias de ensinagem, o que mediará a aprendizagem do aluno que apresenta muita experiência, mas pouco poder de sistematização de conhecimentos e informações, seja, por falta de ter estudado em tempo adequado ao seu desenvolvimento, seja, por falta de professores de qualidade. Nesse sentido, ser um professor que faça a diferença no ensino da matemática significa estar sempre capaz de verse um eterno aprendiz para que possa com maestria, enfrentar os desafios impostos pela vida e as mudanças de paradigmas sóciopolítico-econômicos que se apresentam no cotidiano escolar, muitas vezes, impostos de maneira vertical, pelos governantes. Por certo, professores de qualidade são os que estão sempre explorando, questionando, problematizando as situações mais simples impostas pela vida.

\section{Discussões}

Durante quatro meses trabalhando com alunos da EJA, buscamos enfrentar as necessidades e dificuldades de aprendizagem dos mesmos nas aulas de matemática, considerando muito mais os estudos da neurociência do aprendizado - o que nos levou a elaboração de atividades diversificadas considerando situações caseiras, do comercio, dos esportes, das artes, culinária relacionada a poder aquisitivo familiar, e, muita atividade que remetesse a total descontração ao ambiente de aprendizagem, ou seja, incluindo o lúdico na realização das tarefas através das técnicas de dinâmicas de grupo tendo como carro chefe, a pesquisa e discussão de ideias matemáticas. Vimos e compreendemos que trabalhar a partir dos conhecimentos prévios é muito simples quando se aplica métodos e técnicas que norteiam todo o trabalho, como por exemplo: trabalhar a proporção a partir da receita de um prato comum da culinária local mudando as proporções pré-estabelecidas; trabalhar tabela a partir de informações sobre futebol, 
acontecimentos, fatos; trabalhar a geometria a partir de uma obra de um artista plástico como, por exemplo, Salvador Dali - educando o olhar do aluno e aluna para verem em perspectiva, aprimorando o gosto e abrindo vistas e possibilidades de saberes antes desconhecidos.

Por fím, concluímos que a Matemática, não dever ser um conhecimento aprisionado ao contexto escolar e seus desenhos curriculares engessados, mas sim, elemento da cultura como primeira e importante referência. Portanto, é significativo dominar o método de aprendizado da matemática - o que torna elementar que o professor dessa forma, modele, e, a cada aula, aprimore sua forma de atuação juntos aos alunos visualizando com mais competência suas necessidades básicas de aprendizagem - embora esteja o relativismo sempre presente, haja vista, jamais podermos mensurar a total capacidade da mente do sujeito que aprende - isso nos leva a lembrança que durante os estudos, as pesquisas neurocientíficas, didáticas, metodológicas, apresentaram-se sempre numa condição aproximativa e interpretativa - todavia sem sombra de dúvida, capazes de dar suporte impar aos momentos de ensino e aprendizagem através de um plano de aula bem elaborado. Pois, nossa atuação como professores de matemática, traduz nossa crença de como a criança, o jovem ou adulto produz o conhecimento, em especial, como ele aprende a matemática, quais são seus potenciais, onde estão e, como superaram suas dificuldades. Para uma próxima etapa da pesquisa, já planejamos avaliar o desenvolvimento do aluno na sua construção e como saber qual a melhor forma de contribuir com a constituição do ser matemático considerando suas dificuldades, limitações e características individuais aplicadas no momento da aprendizagem.

\section{Referências}

BEAR, M. F.; CONNORS, B. W.; PARADISO, M. A. Neurociências: desvendando o sistema nervoso. 2. ed. Porto Alegre: Artmed, 2002.

BOGDAN, R.; BIKLEN, S. Características da investigação qualitativa. In: Investigação qualitativa em educação: uma introdução à teoria e aos métodos. Porto, Porto Editora, 1994. p.47-51.

COSENZA, Ramom M. e GUERRA, Leonor B. Neurociência e educação: Como o cérebro aprende. Porto Alegre: Artmed, 2011.

DOMINGUES, M.A. Desenvolvimento e aprendizagem: o que o cérebro tem a ver com isso. Canoas: Editora da ULBRA, 2007.

KOLB, Bryan; WHISHAW, Ian Q. Neurociência do Comportamento. Barueri: Editora Manole Ltda., 2002.

MARCONI, M. D. A.; LAKATOS, E. M. Técnicas de pesquisa. São Paulo: Atlas, 1996.

PICONEZ, Stela C.B. (coord.) A prática de ensino e o estágio supervisionado. Campinas: Papirus, 2002.

SILVA, A.L.R.Monografia fácil: Ferramentas e exercícios. Campinas: DVS Editora, 2004.

TAMAROZZI, E.; COSTA, R. P. Educação de Jovens e adultos. $2^{\text {a }}$. Ed. Curitiba: Iesde Brasil S.A. 2009. P. 4849. 